\title{
AERODYNAMIC CHARACTERISTIC OF THE ACTIVE COMPLIANT TRAILING EDGE CONCEPT
}

\author{
NIE RUI \\ College of Aerospace Engineering, Nanjing University of Aeronautics and Astronautics, Address \\ Nanjing, 210016, China \\ qtqs1985@163.com \\ QIU JINHAO \\ College of Aerospace Engineering, Nanjing University of Aeronautics and Astronautics, Address \\ Nanjing, 210016, China \\ qiu@nuaa.edu.cn \\ JI HONGLI \\ College of Aerospace Engineering, Nanjing University of Aeronautics and Astronautics, Address \\ Nanjing, 210016, China \\ jihongli@nuaa.edu.cn \\ LI DAWEI \\ College of Aerospace Engineering, Nanjing University of Aeronautics and Astronautics, Address \\ Nanjing, 210016, China \\ lidawei01150115@126.com
}

Published 22 June 2016

This paper introduces a novel Morphing Wing structure known as the Active Compliant Trailing Edge (ACTE). ACTE structures are designed using the concept of "distributed compliance" and wing skins of ACTE are fabricated from high-strength fiberglass composites laminates. Through the relative sliding between upper and lower wing skins which are connected by a linear guide pairs, the wing is able to achieve a large continuous deformation. In order to present an investigation about aerodynamics and noise characteristics of ACTE, a series of $2 \mathrm{D}$ airfoil analyses are established. The aerodynamic characteristics between ACTE and conventional deflection airfoil are analyzed and compared, and the impacts of different ACTE structure design parameters on aerodynamic characteristics are discussed. The airfoils mentioned above include two types (NACA0012 and NACA64A005.92). The computing results demonstrate that: compared with the conventional plane flap airfoil, the morphing wing using ACTE structures has the capability to improve aerodynamic characteristic and flow separation characteristic. In order to study the noise level of ACTE, flow field analysis using LES model is done to provide noise source data, and then the FW-H method is used to get the far field noise levels. The simulation results show that: compared with the conventional flap/aileron airfoil, the ACTE configuration is better to suppress the flow separation and lower the overall sound pressure level.

${ }^{*}$ Corresponding author

This is an Open Access article published by World Scientific Publishing Company. It is distributed under the terms of the Creative Commons Attribution 3.0 (CC-BY) License. Further distribution of this work is permitted, provided the original work is properly cited. 
Keywords: Morphing wing; Active Compliant Trailing Edge; distributed compliance; aerodynamic noise.

\section{Introduction}

Morphing aircraft is a kind of multi-mission aircraft and it can change its own external configuration substantially in order to adapt to different task environments during flight ${ }^{1}$. For aircraft, in order to achieve better fuel economy in flight, aircraft's wings require high maximum lift coefficient during taking-off or landing and high lift-drag ratio during cruising $^{2}$. Adaptive wing is an important research field for this purpose. In all of the research for this purpose, adaptive wing is an important component. The weight of the aircraft is changing due to the consumption of fuel in flight. Morphing aircraft can subtly change the wing's curvature to match the changing weight and get better fuel efficiency. Compared with traditional rigid wing, the multi-mission adaptive wing can achieve higher efficiency and will plays an important role in military and civilian fields ${ }^{3}$.

A main purpose of study on variable camber adaptive wing is to vary the aircraft wing in flight under different situations and environments, in other words, to fully expand ai rcraft's flight envelope. Adaptive wing schemes are mainly divided into the adaptation of complete wings and the adaptation of individual components which is include variable camber leading and trailing edges ${ }^{3}$. On the 1980's, in order to validate the aerodynamic benefits of mission adaptive wing (MAW) system, the U.S. Air Force Research Laboratory (AFRL) refitted an F-111A test aircraft and did some tests ${ }^{4}$. The MAW system consisted of variable camber leading and trailing edges. The wing surface of MAW is seamless, smooth and no discontinuities. The results of flight test show that the flight envelope can be expanded effectively. The important areas can be improved by $20 \%$ and even $100 \%$ in some flight conditions ${ }^{5,6}$.

For the design of high altitude long endurance air vehicle, AFTL and FlexSys Inc. developed a natural laminar flow (NLF) airfoil in a Mission Adaptive Compliant Wing (MACW). This wing uses a variable geometry compliant trailing edge to minimize drag across a wide lift coefficient range to optimize flight performance. This flap system can achieve up to $60 \%$ chord laminar flow on the upper surface. Flight test shown that the cruise lift-drag ratio of wing with compliant flap improved $3.3 \%$.

This paper introduces a novel morphing wing structure known as the Active Compliant Trailing Edge (ACTE) structure. The paper conducts a simulation study to explore the two-dimensional aerodynamic characteristics of Adaptive wing with ACTE. In the simulation study, simulation conditions include low-speed and high-subsonic speed.

\section{Design of the Morphing Wing with ACTE}

\subsection{Initial Concept}

This section introduces the design of variable camber adaptive wing structure with ACTE. For adaptive wing Structure design, main evaluation standards include: continuous deformation ability, high reliability, light weight, and withstand aerodynamic loads. In 
the past, material selection of morphing wing skin mainly was fiber-rubber composites ${ }^{9,10}$. However, the out-of-plane bending stiffness and reliability of the rubber composite is low and it is difficult to apply in the morphing wing skin.

Based on the above reason, the paper internalizes the design idea of the "distributed compliance". Then, a new type Active Compliant Trailing Edge (ACTE) structure was proposed. The ACTE structure made of high strength glass fiber composite material lamination plate. The structure provides variable geometry reshaping of the up and low trailing edge surfaces with smooth or continuous. Materials have high ratio of yield strength to elastic modulus. In the condition of determined structure size, the material with the highest ratio can gain greater deformation before the structure failure. For large scale deformation, under high load application, distributed compliance design concept has a great practical significance ${ }^{11}$. The composite bow is a classic example of distributed compliance mechanism. For large scale deformation, under high load application, distributed compliance design concept has a great practical significance. Therefore, considering distributed compliance conception in morphing wing of camber trailing edge or leading edge structure design research is benefit to satisfy requirement of the aircraft design and feasible.

\subsection{ACTE Structure Design and Manufacturing}

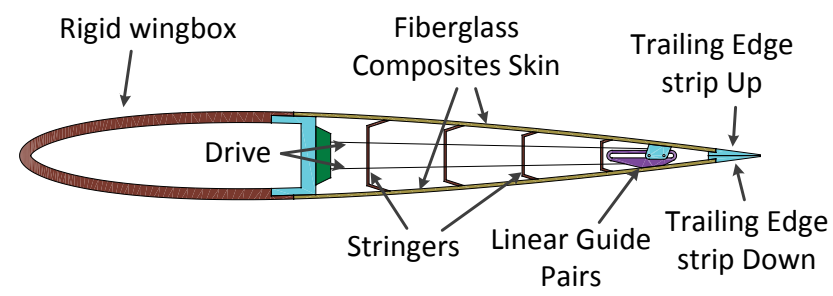

Fig. 1. Active compliant trailing edge concept, based on distributed compliance skins.

Based on the conception of distributed compliance, a novel variable camber adaptive wing structure is proposed (Active Compliant Trailing Edge, ACTE) and depicted in Fig. 1. The ACTE structure can re-contour the wing's upper and lower surfaces and can create large, continuous changes in airfoil camber. The ACTE structure was designed to replace the conventional plane flap. The adaptive wing model is composed of two major parts: the rigid support section and the active compliant trailing edge. The ACTE is connected to the rigid support section seamless and smoothly. The flexible trailing edge is composed of fiberglass composites skin, stringers, linear guide pairs and trailing edge strip. Through the relative sliding between upper and lower wing skins which were connected by a linear guide pairs, the ACTE is able to achieve a large continuous bending deformation. Figure 2 shows a prototype of the ACTE. 


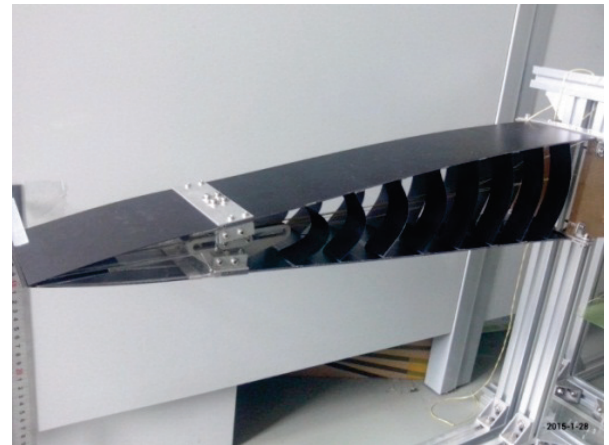

(a) Neutral

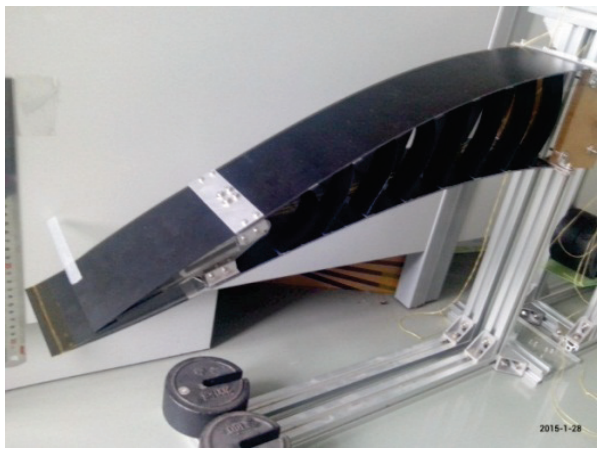

(b) Deflected downwards

Fig. 2. Active Compliant Trailing Edge prototype.

\section{Validation of Method}

Figure 3 presents the computational and experimental pressure coefficient $(\mathrm{Cp})$ distributions of the 2D RAE2822 airfoil. The comparison indicate that the computational results were consistent with the experimental results ${ }^{12}$. However, the computational results were slightly different with the experimental results at the position of shock wave.

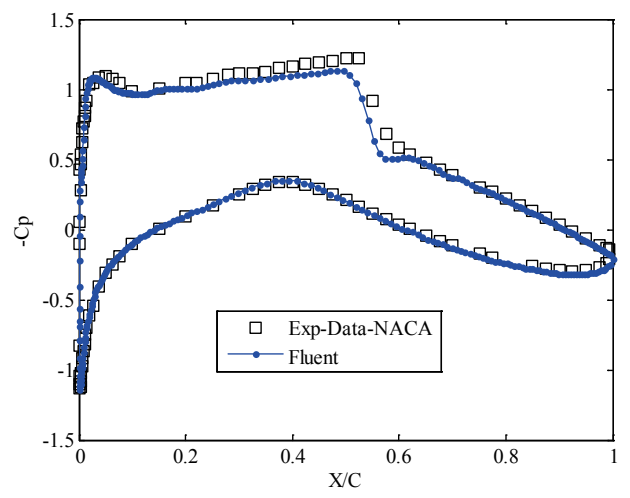

Fig. 3. Pressure distributions.

Table 1 showed the other computational and experimental result ${ }^{12}$ of aerodynamic characteristics. It can be found that the errors of lift coefficient and drag coefficient were less than $2 \%$, which were acceptable. Meanwhile, the shock wave positions between simulation and experiment were close. To sum up, the simulated method is accurate and effective. 
Table 1. Other aerodynamic characteristic.

\begin{tabular}{lllc}
\hline state & $\mathrm{Cl}$ & $\mathrm{Cd}$ & Shock Position(x/c) \\
\hline Experiment & 0.803 & 0.0168 & 0.52 \\
Computation & 0.7912 & 0.0189 & 0.54 \\
Error & $1.47 \%$ & & \\
\hline
\end{tabular}

\section{Low-Speed Aerodynamics Characteristics of Airfoil with ACTE}

In order to investigate the potential aerodynamic performance of camber adaptive wing with the ACTE mechanism, a preliminary study using FLUENT simulation software has been conducted, and NACA0012 airfoil is chosen as a baseline. The shape of deflected trailing edge airfoil is determined by the ATCE's design parameters (the actuators, the skin, the stringers). The deformed shapes were created in finite element analysis software (Nastran and Adams), as shown in Fig. 4. Adopting FEA method, the stress and the deformation of ACTE were obtained. The aerodynamic characteristics of a NACA0012 airfoil with a $60 \%$-chord ACTE was analysed and compared with other type NACA0012 airfoils (a standard NACA0012 airfoil, a NACA0012 airfoil with a 30\%-chord plain flap).

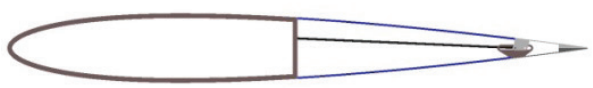

(a) ACTE angle $=0^{\circ}$

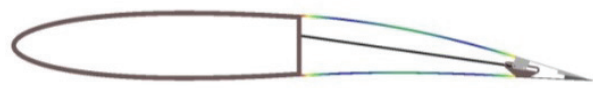

(c) ACTE angle $=10^{\circ}$

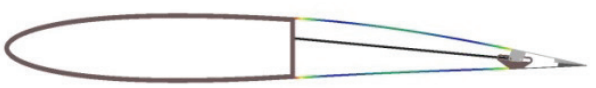

(b) ACTE angle $=5^{\circ}$

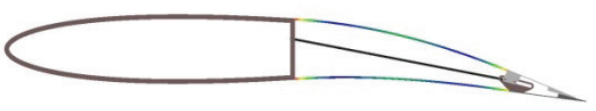

(d) ACTE angle $=15^{\circ}$

Fig. 4. Kinematics modeling and simulation of adaptive wing based on ADAMS.

Fig. 5(a) shows the cross-section of the Conv. TE configuration with a $30 \%$-chord plain, and Fig. 5(b) shows the cross-section of the ACTE configuration. These two figures describe how the trailing edge shifts from the baseline to downward. For the purposes of evaluation and comparing the performance of different airfoil configurations, the deformation angle of trailing edge is defined as the criterion to measure the aerodynamic performance. It can be seen that the ACTE and the plane flap are deflected $20^{\circ}$ relative to $70 \%$-chord point. 


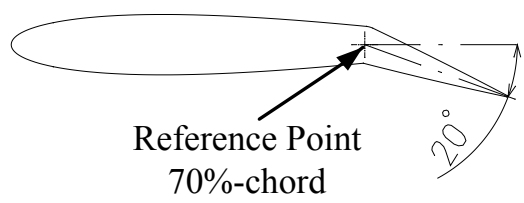

(a) Conv. TE configuration

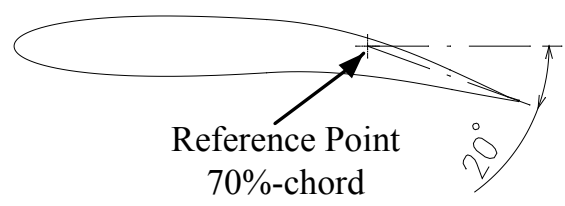

(b) ACTE configuration

Fig. 5. Configuration geometries.

\subsection{Computational Condition}

\subsubsection{Aerodynamic performance simulation condition}

Flow around airfoil is computed using $\mathrm{C}$-grid and SA turbulence model. The computational domain is bounded by the airfoil surfaces and far field boundary, and there is a significantly large distance from the airfoil surface to far field boundary. The airfoil surfaces are no slip wall boundary condition while exterior boundaries are treated as far field boundaries. Table 2 indicates the free stream and model geometry conditions. The flow condition for this simulation case is $\mathrm{Ma}=0.2, \mathrm{Re}=4.36 \times 10^{6}$ and it is a typical flight condition in many general aircrafts (such as Cessna-172). A fine grid of $360 \times 150$ resolution was used, with 360 grid points around the airfoil and 150 points normal to the airfoil extending to the far field boundary that is 25 chords away from the airfoil. Moreover, the Mach number is low enough to avoid significant compressibility effects.

Table 2. Freestream and geometry conditions.

\begin{tabular}{lll}
\hline Mach & Reynolds Number & Chord length \\
\hline 0.2 & $4.36 \times 10^{6}$ & $1000 \mathrm{~mm}$ \\
\hline
\end{tabular}

\subsubsection{Aero-Acoustics simulation condition}

Flow around airfoil is computed using C-grid and Large Eddy Simulation (LES) method. The 2D simulated model consists of 8 face zones and a total of 597800 grids. The chord length of the ACTE model is $1000 \mathrm{~mm}$, the Reynolds number is $6.4 \times 10^{6}$ at the test speed $(\mathrm{Ma}=0.3)$. Pressure far field boundary conditions are used to model a free stream condition to infinity. In order to better simulate the true infinite far condition, far field boundary should be placed far enough from the object. In this case, the distance between pressure far field boundary and the airfoil surface is 25 times of the chord length.

\subsection{Simulation Results}

\subsubsection{Aerodynamic Performance}

Figure 5 shows the variation of lift coefficient (CL) and drag coefficient (CD) considering angle of attack (AOA) change. As predicted, the lift coefficient increases and 
the drag coefficient decreases at certain angle of attack. Compared with conventional plain flap and stranding airfoil, the lift coefficient of ACTE has a significantly improvement when angles of attack is from $-2^{\circ}$ to $12^{\circ}$, as shown in Fig. 6(a). The drag coefficient of ACTE is lower than plain flap and stranding airfoil in the same state, as shown in Fig. 6(b).

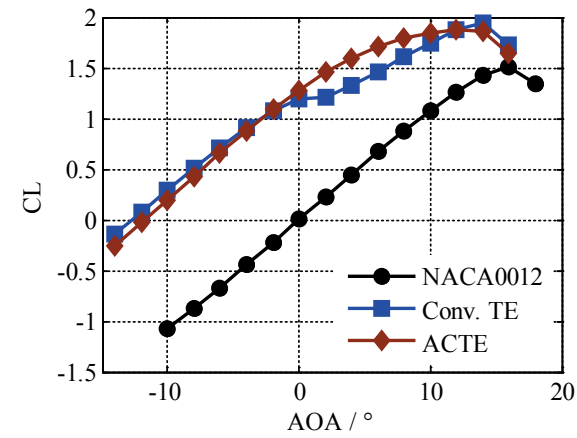

(a) Variation of lift coefficient with AOA

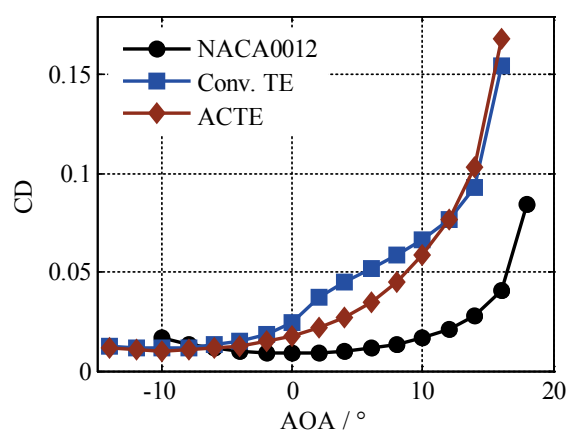

(b) Variation of drag coefficient with AOA

Fig. 6. Lift coefficient, drag coefficient with AOA.

The drag polars for ACTE, the Conv. TE and the NACA0012 airfoil are compared in Fig. 7(a). It can be seen that ACTE results in higher values of lift coefficient in the lowdrag rang $(<0.02)$. When $C L>0.65$, the ACTE has even lower drag than the standard NACA0012 airfoil. When CL $>1.87$, the drag behaviour of ACTE is similar to the Conv. TE.

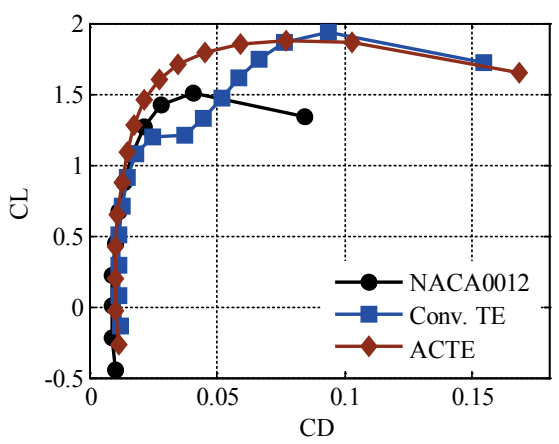

(a) Drag polar

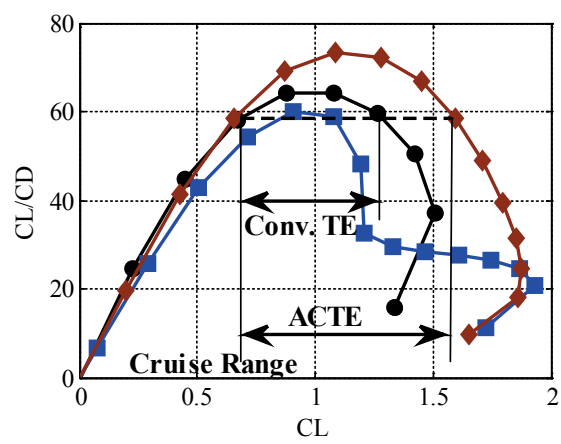

(b) Efficiency (lift to drag ratio) with CL

Fig. 7. Drag polar and Lift-Drag ratio.

Fig. 7(b) shows lift-drag ratio versus lift coefficient plot. The results of simulation show that the airfoil with ACTE achieves notable improvement in lift efficiency (lift-drag ratio) compared with the Conv. TE and the NACA0012. Maximum lift-drag ratio of ACTE has increased 14.3\% compared with the NACA0012 and 24.5\% compared with 
the Conv. TE. It also shows a noticeable increase in the useful cruise range assuming a minimum required lift-drag ratio of 60 .

\subsubsection{Radiation Noise characteristic}

The FW-H acoustic analogy method is more suitable to simulate the far field noise. Through analysis of the acoustic spectrum results, Overall Sound Pressure Level (OASPL) can be obtained.

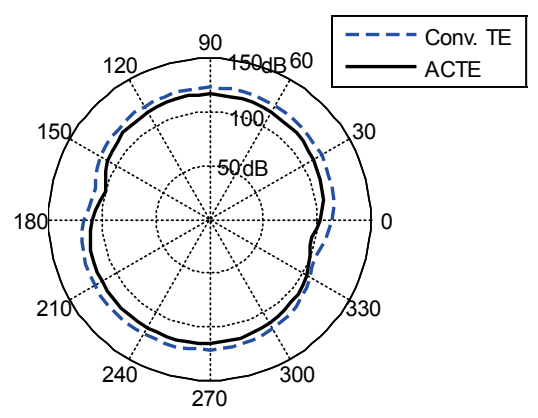

(a) Acoustic directivity results for Far-field

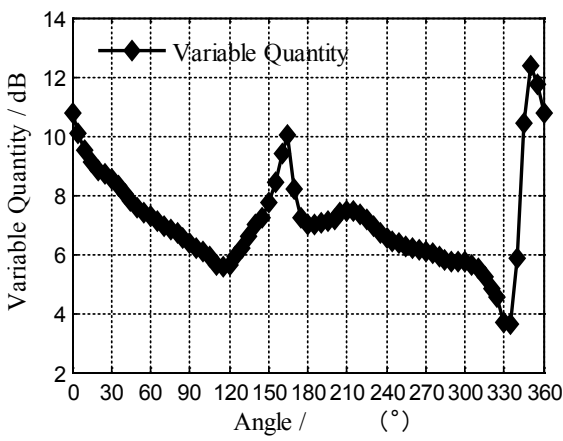

(b) Variable Quantity

Fig. 8. Far-field aerodynamic noise.

Fig. 8(a) illustrates the acoustic directivity results for far field. Fig. 8(b) is the difference between the current value of the ACTE and the Conv. TE. The directivity of the OASPL is obtained by 72 observer points. These observer points are located on the circle edges. The circle radius is ten times chord length, and the center of circle is coincided with the airfoil center. Comparing the results, it is found that the ACTE can reduce the OASPL on the emission region. It is shown that the OASPL of ACTE decreased $7 \mathrm{~dB}$ in average.

\section{Aerodynamic Characteristics of Airfoil with ACTE under High Subsonic Flow}

The plain flap is used to not only take off and land, but also improve the high-subsonic speed aero characteristics as maneuvering flap. Plenty of studies have revealed that a wing with a variable flap in a small angle can reduce drag and increase lift. In this section, the main research content is the performance of ACTE as maneuvering flap.

The NACA64A005.92 was chosen as the original airfoil. The aero characteristics of 4 kinds of configurations were analyses. Fig. 9 shows four airfoil geometries used in this study, and Table 3 shows the model definition. 


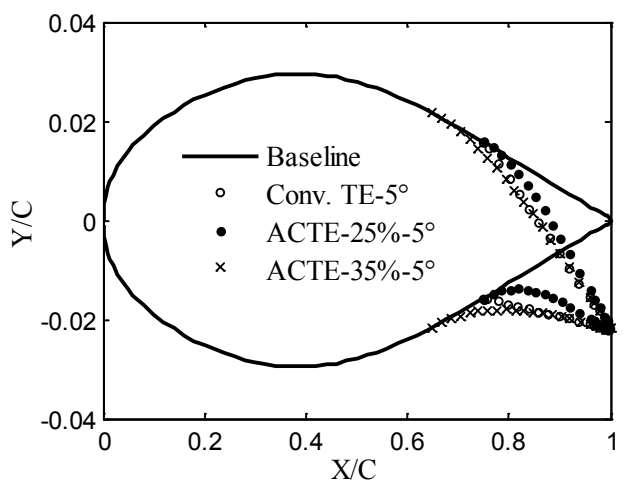

Fig. 9. Geometries for the ACTE configurations and the baseline.

Table 3. Definition of VCCTEF Configurations

\begin{tabular}{lll}
\hline Configuration & Flap deflect, deg & Notation \\
\hline Baseline & & Baseline \\
Plain falp & 5 & Conv. TE- $5^{\circ}$ \\
$25 \%$ chord ACTE & 5 & ACTE- $25 \%-5^{\circ}$ \\
$35 \%$ chord ACTE & 5 & ACTE- $35 \%-5^{\circ}$ \\
\hline
\end{tabular}

\subsection{Computational Condition}

A fine C-grid of $360 \times 150$ resolution was used, with 360 grid points around the airfoil and 145 points normal to the airfoil extending to the far field boundary that is located 25 chords away from the airfoil. The cell height at the wall is $4.2 \times 10^{-5} \mathrm{~m}\left(\mathrm{Y}^{+}<5\right)$. During the simulation, the SST turbulent model is adopted. Each of the airfoil was calculation over a range of angles of attack at two different Mach numbers, and analysis parameters are shown in Table 4.

Table 4. Analysis parameters.

\begin{tabular}{lll}
\hline Parameter & Value & Units \\
\hline Baseline airfoil & NACA64A005.92 & \\
Chord, c & 1000 & $\mathrm{~mm}$ \\
Morphing start x/c & $0.65,0.75$ & \\
Mach & 0.8 & \\
\hline
\end{tabular}

\subsection{Simulation results}

The CL-AOA plots at $0.8 \mathrm{Ma}$ for four aifoils are shown in Fig.10. It can be seen form the graph that the results of four airfoils have a similar trend. More specifically, the trend can be divided into 3 parts (jump part, increase part, decline part) in order. Compared with the baseline airfoil, ACTE and plain flap configurations can obviously improve the 
maximum lift, and ACTE-25\%-5 $5^{\circ}$ made the largest improvement. The maximum lift coefficient increment of ACTE- $25 \%-5^{\circ}$ configuration is 0.23 and has a $27 \%$ increase than the baseline airfoil, whereas the Conv. TE- $5^{\circ}$ only increase by $22 \%$ than the baseline airfoil.

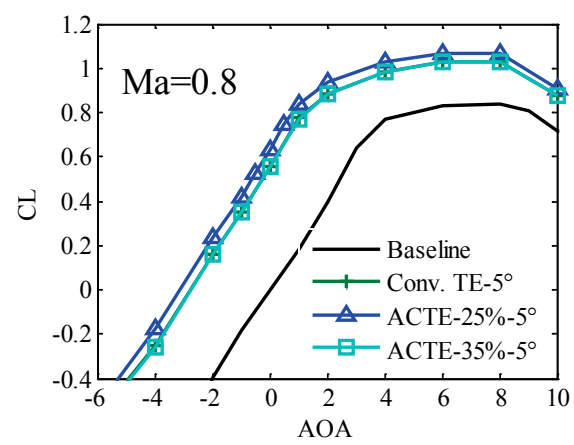

Fig. 10. Baseline and other aifoil comparison: variation of lift with AOA.

The drag polar for four airfoils are compared in Fig. 11(a). The graph shows the advantage of the ACTE configuration. When the lift coefficient is 0.8 , the drag coefficient of ACTE- $25 \%-5^{\circ}$ is 0.02 , smaller than Conv. TE (0.025) and ACTE-35\%-5 (0.065). Between the three types of trailing edge shape, the performance of ACTE-25\%$5^{\circ}$, low drag over a wide lift coefficient range from 0.4 to 0.7 , is excellent. So the ACTE configuration can be used to optimize the airfoil shape and increase laminar flow extent.

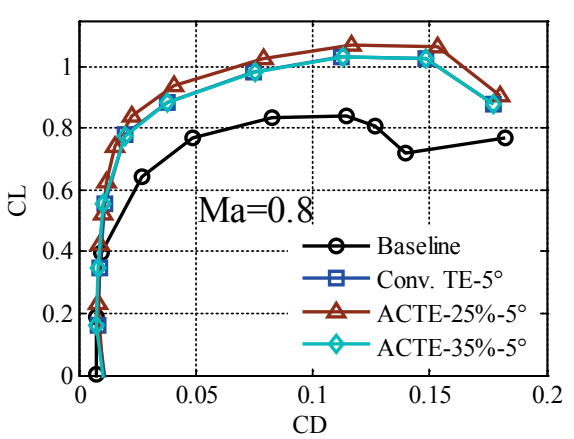

(a) Drag polar

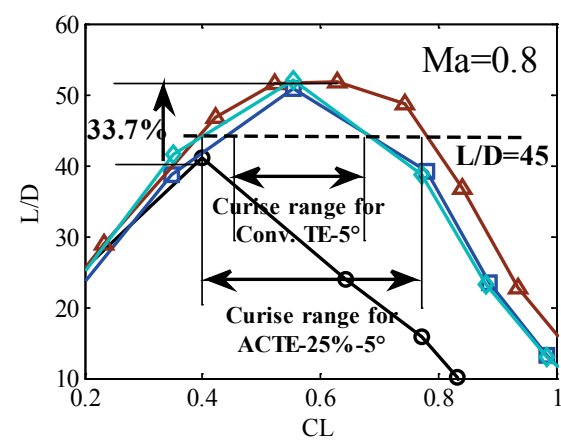

(b) Efficiency (lift to drag ratio) with CL

Fig. 11. Drag polar and Lift-Drag ratio.

The potential advantage of the ACTE is demonstrated in Fig. 11(b). The graph shows that the maximum lift-drag ratio of the ACTE and plain flap configuration increase by $33.7 \%$ compared with the baseline. Assuming the minimum required lift-drag ratio in the cruise is 45 , the ACTE can extend cruising range effectively.

Figure 12 shows the pressure coefficient distributions in different conditions $\left(\mathrm{AOA}=0^{\circ}, 1^{\circ} ; \mathrm{Mach}=0.8 ;\right.$ Altitude $\left.=11000 \mathrm{~m}\right)$. There is a significant pressure peak at flap 
$\mathrm{knee}(\mathrm{X} / \mathrm{C}=0.75)$ on the upper surface of the Conv.TE- $5^{\circ}$ airfoil and $\mathrm{ACTE}$ configurations do not have this phenomenon, as shown in Fig.12. Compared with the conventional plane flap airfoil, ACTE- $25 \%-5^{\circ}$ configuration is able to postpone the appearance position of shock wave (from $\mathrm{X} / \mathrm{C}=0.63$ to $\mathrm{X} / \mathrm{C}=0.68$ ).

When $\mathrm{AOA}=0^{\circ}$, the pressure gradient of ACTE- $25 \%-5^{\circ}$ on the upper surface over the first $68 \%$ of the model chord remains favourable thus keeping the boundary layer laminar. In essence, therefore, the reason the performance improvement of ACTE configuration is the chord-wise load redistribution.

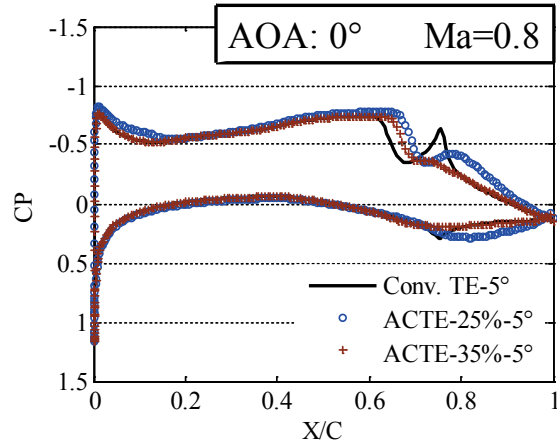

(a) $\mathrm{Cp}$ for $0^{\circ}$ of $\mathrm{AOA}$

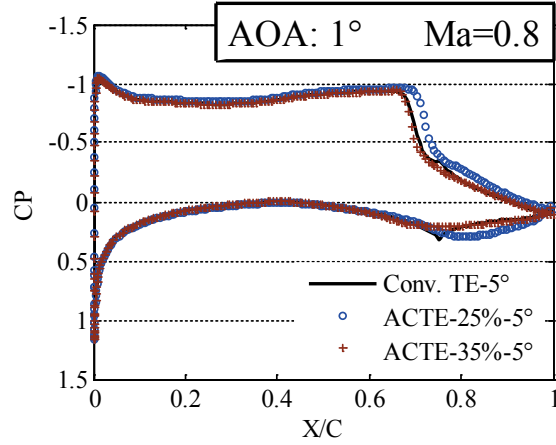

(b) $\mathrm{Cp}$ for $1^{\circ}$ of $\mathrm{AOA}$

Fig. 12. Pressure coefficient distributions in different conditions.

Figure 13 shows the corresponding Mach number variation. An assumption is made that the gas is perfectly ideal and the air flux is isentropic flow. Then the relationship between pressure coefficient and Mach number can be obtained, as shown in the Eq. (1).

$$
M a=\sqrt{\frac{2}{\gamma-1}\left[\left(1+\frac{\gamma-1}{2} M a_{\infty}^{2}\right)\left(1+\frac{\gamma}{2} M a_{\infty}^{2} C p\right)^{-\frac{\gamma-1}{\gamma}}-1\right]}
$$

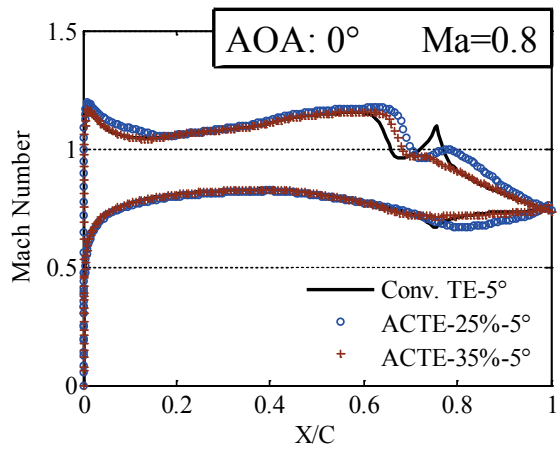

(a) Mach number for $0^{\circ}$ of $\mathrm{AOA}$

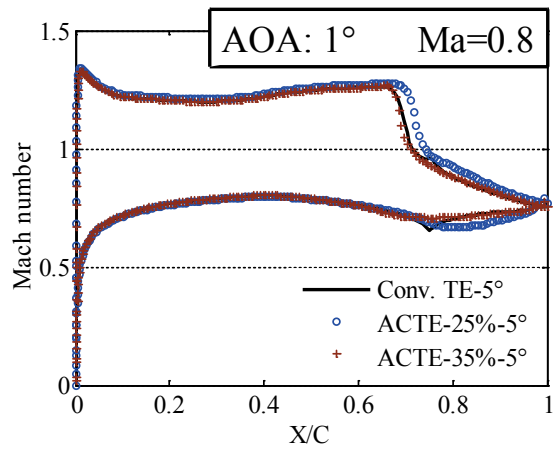

(2) Mach number for $0^{\circ}$ of AOA

Fig. 13. Mach number distributions in different conditions. 
Above research result indicates that a suitable ACTE design can improve the aerodynamic characteristic of aircraft wing. The locus of combined different active compliant trailing edge deformations providing minimum drag as function of lift constitutes the envelope line, the result shown in Fig. 14.

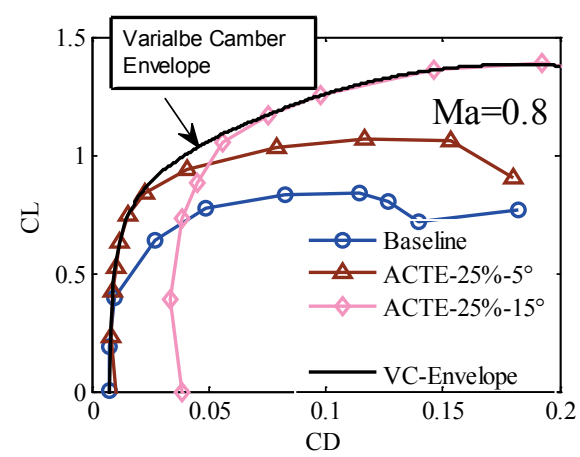

Fig. 14. Variable-Camber envelope line for the ACTE.

\subsection{The Three-dimensional Wing aerodynamic efficiency simulation result}

The study of sections 5.1 and 5.2 is about two-dimensional airfoils. In this section (5.3) three-dimensional wing is studied.

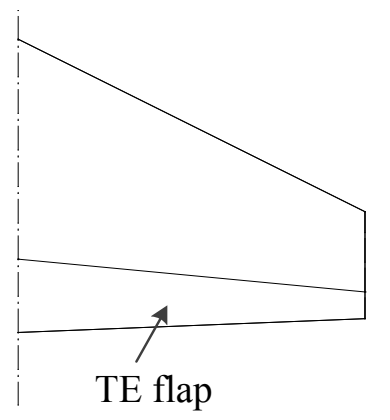

(a) Planform view of swept wing

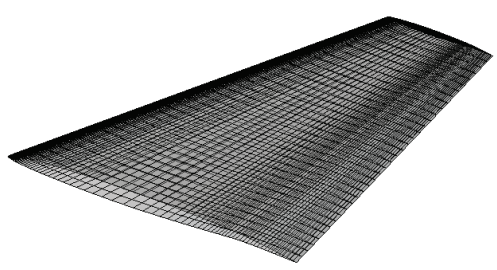

(b) Three-dimensional swept wing

Fig. 15. TE flaps on a three-dimensional swept wing. 


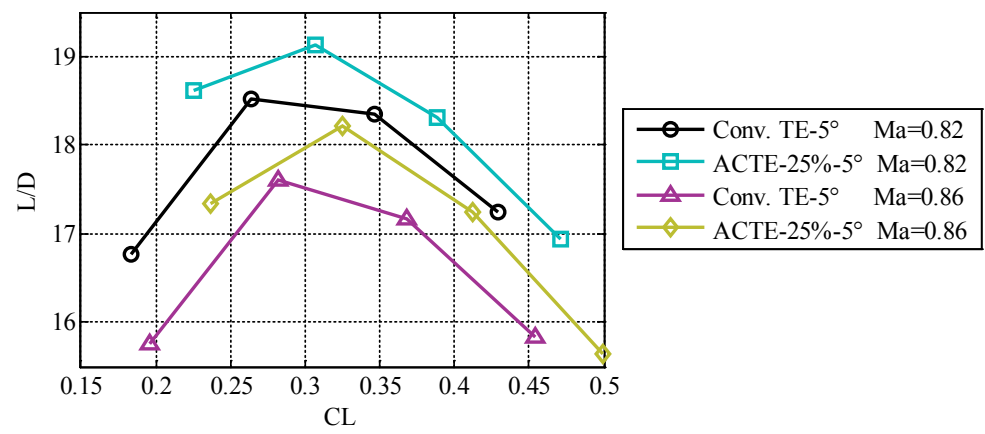

Fig. 16. Swept Three-dimensional Wing Efficiency (lift to drag ratio) with CL.

Fig. 15(a) shows the planform view of a three-dimensional swept wing with trailing edge flap. Fig. 15(b) shows the three-dimensional swept wing. Fig.16 shows lift-drag ratio versus lift coefficient plot of the three-dimensional swept wing. When $\mathrm{Ma}=0.82$, the $\max \mathrm{L} / \mathrm{D}$ of ACTE- $25 \%-5^{\circ}$ is 19.1 , Conv. TE- $5^{\circ}$ is 18.5 . When $\mathrm{Ma}=0.86$, the $\max \mathrm{L} / \mathrm{D}$ of ACTE is 18.1 , Conv. TE- $5^{\circ}$ is 17.6 . To sum up, the wing with ACTE- $25 \%-5^{\circ}$ can achieve higher aerodynamic efficiency in high subsonic. It is shown that the threedimensional wing has the same trend of aerodynamic efficiency compared with twodimensional airfoils.

\section{Concluding Remarks}

This article presents the results of structural design and CFD simulation performed on a morphing wing concept based on distributed compliance mechanism. The performance of the morphing wing is assessed, leading to the following conclusions:

1. Simulation results show that the airfoil with ACTE achieves notable improvement in lift efficiency (lift-drag ratio) compared with the Conv. TE and the NACA0012. Maximum lift-drag ratio of ACTE has increased $14.3 \%$ compared with the NACA0012 and $24.5 \%$ compared with the Conv. TE at low speed.

2. The ACTE can reduce the OASPL on the emission region at $\mathrm{Ma}=0.3$.

3. The NACA64A005.92 was chosen as the original airfoil. Assuming the minimum required lift-drag ratio in the cruise is 45 , the ACTE can extend cruising range effectively. When $\mathrm{AOA}=0^{\circ}$, the pressure gradient of ACTE- $25 \%-5^{\circ}$ on the upper surface over the first $68 \%$ of the model chord remains favourable thus keeping the boundary layer laminar.

4. The three-dimensional wing has the same trend of aerodynamic efficiency compared with two-dimensional airfoils.

\section{Acknowledgments}

This work is supported by "the National Natural Science Foundation of China" (No. 11372133), "the Fundamental Research Funds for the Central Universities" (No. 
NE2015101 \& NE2015001) and "A Project Funded by the Priority Academic Program Development of Jiangsu Higher Education Institutions (PAPD)".

\section{References}

1. Armando R Rodriguez, "Morphing aircraft technology survey,"AIAA Paper, Vol. 1258, (2007), pp. 2007.

2. Michael Sinapius, Hans Peter Monner, Markus Kintscher and Johannes Riemenschneider, "DLR's Morphing Wing Activities within the European Network, "Procedia Iutam, (2014), pp. 416-426.

3. 02E. Stanewsky, "Adaptive wing and flow control technology,"Progress in Aerospace Sciences, Vol. 37, No. 7 (2001), pp. 583-667.

4. William W Gilbert, "Mission adaptive wing system for tactical aircraft,"Journal of Aircraft, Vol. 18, No. 7 (1981), pp. 597-602.

5. Stephen B. Smith and David W. Nelson, "Determination of the aerodynamic characteristics of the mission adaptive wing,"Journal of Aircraft, Vol. 27, No. 11 (2012), pp. 950-958.

6. Ronald W Decamp and Richard Hardy, "Mission Adaptive Wing Advanced Research Concepts,"Aiaa Atmospheric Flight Mechanics Conference|a Collection of Technical Papers Aug, (1999).

7. Joel Hetrick, "Flight Testing of Mission Adaptive Compliant Wing,"Aiaa Journal, (2007).

8. Harold Youngren, "Multi-Point Design and Optimization of an Natural Laminar Flow Airfoil for a Mission Adaptive Compliant Wing,"Aiaa Journal, (2000).

9. C Thill, J Etches, I Bond, K Potter and P Weaver, "Morphing skins,"The Aeronautical Journal, Vol. 112, No. 1129 (2008), pp. 117-139.

10. Gabriel Murray, Farhan Gandhi and Charles Bakis, "Flexible matrix composite skins for onedimensional wing morphing,"Journal of Intelligent Material Systems and Structures, Vol. 21, No. 17 (2010), pp. 1771-1781.

11. Larry L Howell, Compliant mechanisms (John Wiley \& Sons, 2001).

12. Zhonghua Han, Zhide Qiao and Juntao Xiong, "Development of an Efficient Viscous Preconditioning Method and Its Application to Numerical Simulation of Flows over Airfoils,"Journal of Northwestern Polytechnical University, Vol. 24, No. 3 (2006), pp. 275280 . 